\title{
Multi-objective optimal allocation of regional comprehensive energy considering electricity trading
}

\author{
Linfeng Wang ${ }^{1, *}$, Bo Zhou ${ }^{1}$, Jing Nie ${ }^{1}$, Yan Song ${ }^{1}$, and Dongchao Wang ${ }^{1}$ \\ ${ }^{1}$ State Grid Hebei Economic Research Institute, Hebei, 05000, China
}

\begin{abstract}
In order to promote the coordination of various forms of energy resources such as electric energy, heat energy, and cold energy, and to achieve complementary and efficient use of different energy sources, a method for optimizing the allocation of the capacity of a regional comprehensive energy system that takes into account the trading of electric and thermal energy is proposed. The energy interaction costs of the system and the grid heat network are included in the total cost. The optimization goal is a multi-objective function that comprehensively considers system economics, environmental protection, reliability, and interactive power fluctuations. Based on the energy hub, the capacity of each energy supply equipment in the area is optimized. Time-sharing electricity price and typical daily system economic operation are solved by genetic algorithm. Finally, an example of a park is used to verify its effectiveness. The results show that the proposed method can effectively reduce the system cost and reasonably avoid the limitations caused by the single decision factors in the system planning stage, thus providing a reference for the actual system planning and design.
\end{abstract}

\section{Introduction}

With the rapid development of the social economy, the contradiction between the growth of energy demand and the shortage of energy is becoming increasingly prominent. This is because in traditional energy systems, energy, heat, cooling and other energy subsystems are often independent of each other in design, planning, operation and control. As a result, the overall energy utilization rate is not high, and safety and reliability are reduced. In this context, through the coupling of various energy sources such as natural gas, electricity, heat and cooling, all energy links are organically coordinated and optimized to achieve the efficient use of renewable energy and meet the user's multiple energy needs. An integrated energy system, IES) came into being. Demonstration projects and research projects on integrated energy systems have been carried out at home and abroad, such as the EU ELECTRA demonstration project [1-2]. At present, there has been some research on the optimal allocation of regional integrated energy systems. Reference [3] proposed a threelevel collaborative overall optimization design method for a combined heat and cold power supply system, and proved its effectiveness by comparing two types of combined heat supply systems: "determine electricity with heat" and "determine heat with electricity". However, the research only focused on the cogeneration system without considering the renewable energy factor. Literature [4] established a robust optimized capacity allocation model for an independent AC microgrid, and based on the Berder decomposition method, iteratively solved problems interactively to verify the validity of the model. Literature [5] establishes an improved demand-side response model, and on this basis, uses the GA-PS combined intelligent algorithm to solve with the minimum total cost as the optimization goal. However, the literature only considers the planning of distributed power sources such as wind and solar storage, and has not conducted in-depth studies on the coupling of power systems and heating and cooling systems. Literature [6] proposed an optimized planning framework for energy hubs to solve the capacity allocation problems of multi-energy systems such as combined heat and power, boilers, electricity storage and heat storage. However, there is a lack of comprehensive consideration of economics, environmental protection, and reliability, and the planning goals for the energy system are relatively single. In summary, further research is needed on the diversification of energy equipment in multi-energy systems, the interactivity and reliability of electrothermal energy. To this end, this paper proposes a method for optimizing the allocation of the capacity of a regional integrated energy system that takes into account the trading of electrical and thermal energy. The energy interaction costs with the higher-level power grid heating network are included in the objective function. The optimization objective comprehensively considers economic costs, environmental benefits, and reliable energy supply The factors of system performance and system power fluctuation are based on time-sharing electricity price and typical daily economic operation of the system, and are solved by genetic algorithm to achieve the optimal capacity allocation of the system.

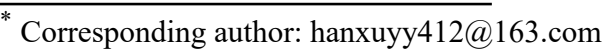




\section{Structure of integrated energy system}

An integrated energy system is a complex system that integrates a variety of energy resources of different natures, and achieves cascade utilization of energy and promotes sustainable development of energy through complementary mutual assistance among energy sources. Simply divided into three levels: (1) Energy input side: mainly including wind energy, solar energy, natural gas, as the energy foundation of the regional integrated energy system, supporting and guaranteeing the basic operation of the system. (2) Energy coupling part: It is the manifestation of the complexity of the regional comprehensive energy system, including multiple energy forms and energy links. (3) Energy output side: The equipment components of the energy coupling part will finally transmit the energy generated by the system to the end user through their respective lower-level energy transmission networks to meet their energy requirements for cooling, heating and electricity loads.

The regional integrated energy system is located at the lower layer of the energy bus, and can realize the interaction with the bus. It can absorb energy from the bus and provide energy for it. The energy bus contains various energy types such as electric energy and heat energy. Due to the difference in energy demand and market price in each operating period of the regional integrated energy system, considering the difference and complementarity of the electric energy interaction with the energy bus in the optimal configuration will help reduce the system operating cost and increase the utilization rate of renewable energy to promote comprehensive and optimal utilization of multiple energy sources. Therefore, this paper considers the energy interaction between the system and the energy bus including the power grid and the heat grid, and establishes the energy interaction structure of the comprehensive energy system with multiple energy grids.

\section{Comprehensive energy multi-objective optimization configuration model}

\subsection{Optimizing configuration goals}

The optimized configuration model established in this paper takes into account the two aspects of system economy and environmental protection. The objective function includes equipment investment cost, operation and maintenance cost, electrothermal energy transaction cost, pollutant emission, etc.

$$
\min G_{I E S}=G_{E C O}+G_{E N V}
$$

(1) Economy

$G_{E C O}$ includes initial investment cost $C_{I N V}$, operation and maintenance cost $C_{O M}$, electricity transaction cost $C_{D J}$ and heat transaction cost $C_{R J}$.

$$
\begin{aligned}
G_{E C O} & =C_{I N V}+C_{O M}+C_{D J}+C_{R J} \\
C_{I N V} & =\sum_{m} C_{i n v},{ }_{m} \lambda_{m} \mu_{C R F}(r, Y)
\end{aligned}
$$

$$
\mu_{C R F}(r, Y)=\frac{r(1+r)^{Y}}{(1+r)^{Y}-1}
$$

$C_{i n v},{ }_{m}$ is the investment cost per unit capacity of equipment $\mathrm{m} ; \lambda_{m}$ is the installed capacity of each device; $\mu_{C R F}(r, Y)$ is the fund recovery factor and it represents one-time investment cost converted to annual expenses; $Y$ is the service life of the equipment; $r$ is the base discount rate of $6.7 \%$.

$$
C_{O M}=\sum_{n} d_{n} \sum_{m} \sum_{t=1}^{24}\left(C_{o m, m} P_{t, m, o u t} \Delta t+\frac{c_{g a s} F_{t, m} \Delta t}{Q_{g a s}},\right.
$$

$C_{o m, m}$ is the operation and maintenance cost of the unit $\mathrm{m}$ output energy of the equipment; $P_{t, m, \text { out }}$ is the output of the equipment $\mathrm{m}$ in the period $\mathrm{t} ; \Delta t$ is the length of time; $c_{\text {gas }}$ is the price of natural gas; $F_{t, m}$ is the gas consumption of equipment $\mathrm{m}$ in period $\mathrm{t} ; Q_{\text {gas }}$ is the calorific value of natural gas.

$$
\begin{aligned}
& C_{D J}=\sum_{n} d_{n} \sum_{t=1}^{24}\left(\frac{\left(C_{t, D b y y}-\alpha C_{t, D \text { sell }}\right)}{2}\left|P_{t, D J}\right|+\frac{\left(C_{t, \text { Dbly }}-\alpha C_{t, \text { Dell }}\right)}{2} P_{t, D J}\right) \\
& C_{R I}=\sum_{n} d_{n} \sum_{t=1}^{24}\left(\frac{\left(C_{t, R h y y}-\beta C_{t, \text { Reel }}\right)}{2}\left|H_{t, R \mid}\right|+\frac{\left(C_{t, R h y y}-\beta C_{t, \text { Rell }}\right)}{2} H_{t, R J}\right)
\end{aligned}
$$

$C_{t, \text { Dbuy }}$ and $C_{t, \text { Dsell }}$ are the purchase and sale prices of the system to the spider web at time t; $C_{t, R b u y}$ and $C_{t, \text { Rsell }}$ are the hot price of the system to the hot network at time $\mathrm{t} ; P_{t, D J}$ is the interactive power between the system and the grid at time t. $H_{t, R J}$ is the interactive power between the system and the superior heat network at time $t$.

(2) Environmental protection

This article takes $\mathrm{CO}_{2}$ and $\mathrm{NO}_{\mathrm{x}}$ emissions as indicators to measure the environmental protection of integrated energy systems. $\mathrm{CO}_{2}$ emissions come from two parts: emissions from natural gas fuel consumption and electricity purchase; $\mathrm{NO}_{\mathrm{x}}$ emissions come from emissions from system equipment.

$$
\begin{gathered}
G_{E N V}=\xi_{C O_{2}}+\xi_{N O_{x}} \\
\xi_{\mathrm{CO}_{2}}=\sum_{n} d_{n} \sum_{t=1}^{24}\left(k_{a} F_{\mathrm{t}, G T}+k_{a} F_{\mathrm{t}, G B}\right)+\sum_{n} d_{n} \sum_{t=1}^{24} k_{b} P_{\mathrm{t}, D T} \\
\xi_{N O_{x}}=\sum_{n} d_{n} \sum_{t=1}^{24} k_{c} \sum_{m} P_{t, m, \text { out }} \Delta t
\end{gathered}
$$

$k_{a} 、 k_{b}$ and $k_{c}$ are the pollutant emission coefficients of natural gas, power and system equipment, respectively.

\subsection{Restrictions}

$$
P_{t, W T}+P_{t, P V}+P_{t, G T}+P_{t, D J}=P_{t, P L}+P_{t, E C}+P_{t, H P}
$$




$$
\begin{gathered}
H_{t, R J}+H_{t, G B}+H_{t, H P}+H_{t, W H}=H_{t, H L}+H_{t, A C} \\
Q_{t, A C}+Q_{t, E C}=Q_{t, C L} \\
0 \leq \lambda_{m} \leq \lambda_{m, \max } \\
P_{t, m \text { min }} \leq P_{t, m} \leq \lambda_{m} \\
P_{t, D J \min } \leq P_{t, D J} \leq P_{t, D J \max } \\
H_{t, R J \min } \leq H_{t, D J} \leq H_{t, R J \max }
\end{gathered}
$$

$P_{t, P L} 、 H_{t, H L}$ and $Q_{t, C L}$ are the system electrical load, thermal load and cooling load value at time.

\subsection{Optimization model solution process}

Since the optimal configuration objective function is composed of the goals related to the planning capacity variables and the system operating variables, it is divided into two aspects: optimization configuration and optimization operation. The upper optimization variables are equipment capacity and the lower optimization variables are each the operation output of multi-energy equipment and the interactive power value of the system and the power grid and heating network. The solution process of the multi-objective model is shown in the figure below.

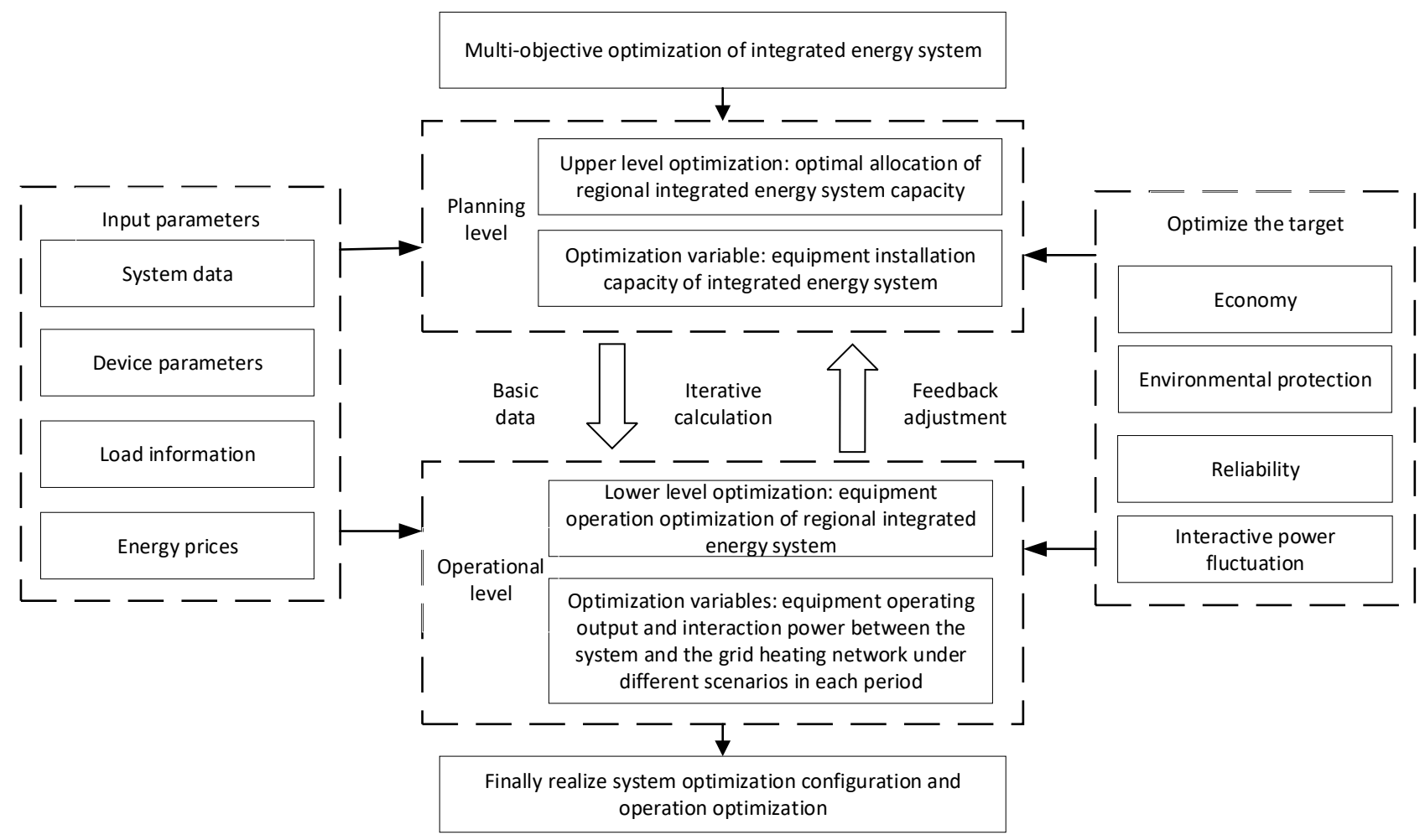

Fig. 1. Multi-objective model solving process.

\section{Example analysis}

\subsection{Study parameters}

This article takes a northern region in my country as the research object, and verifies the effectiveness and practicability of the proposed method based on the abovementioned optimal allocation model. Since the cooling and heating load is greatly affected by the seasons, the load difference is significant in different seasons, and the load difference is relatively small in most seasons of the same season, this paper divides the whole year into winter (November to March) and summer based on the obvious seasonal characteristics of the load (May-October) and the transition season (that is, spring and autumn April) constitute three typical day scenes (that is, $n=3$ ). The duration of each scene is 110,153 , and 102 days. Continuous calculations are carried out throughout the year, taking into account both calculation accuracy and calculation complexity. According to the local wind speed and lighting conditions, the ratio curve of wind power, photovoltaic output and installed capacity and the electric heating and cooling load value of the corresponding season are calculated.

\subsection{Analysis of calculation results}

In this example, the genetic algorithm is used to solve. The parameters in the algorithm are: population size $\mathrm{N}$ and iteration number $\mathrm{k} \max$ is 100 . In order to verify the advantages of the comprehensive energy system that considers electric heat trading, that is, system 3 , this paper introduces system 1 and system 2. Compared with it, System 1 is a traditional distribution system (SP), that is, the electric load is only provided by the power grid, the heat load is provided by the gas boiler, and the cooling load is provided by the electric refrigerator's power consumption; System 2 is the power supply only with the power grid interactive integrated energy system, and the 
optimized results of each system are shown in the table below.

Table 1. Comparison of optimization results of various systems.

\begin{tabular}{|c|c|c|c|c|}
\hline \multirow[b]{2}{*}{ system } & \multicolumn{3}{|c|}{ Economic/10,000 yuan } & \multirow[b]{2}{*}{$\begin{array}{c}\text { Environmental } \\
\text { protection } \\
\text { Reliability } \\
\text { (CO2 and NOx } \\
\text { emissions/t) }\end{array}$} \\
\hline & $\begin{array}{c}\text { Investment } \\
\text { operation and } \\
\text { maintenance } \\
\text { cost }\end{array}$ & $\begin{array}{c}\text { Electricity } \\
\text { transaction } \\
\text { cost }\end{array}$ & $\begin{array}{l}\text { total } \\
\text { cost }\end{array}$ & \\
\hline 1 & 959 & 4571.9 & 5531 & 44366 \\
\hline 2 & 4310 & -287.92 & 4022 & 15268 \\
\hline 3 & 4031 & -451.45 & 3580 & 15046 \\
\hline
\end{tabular}

Since the four-year trend of electric load is similar and the cooling and heating load has obvious seasonality, the optimal operation of the collector and the collector is selected in winter and summer, respectively, for analysis.

Table 2. Electricity and heat transaction on typical days.

\begin{tabular}{|c|c|c|c|c|}
\hline \multirow{2}{*}{ Typical day } & \multicolumn{2}{|c|}{$\begin{array}{c}\text { Electricity trading (with } \\
\text { grid) }\end{array}$} & \multicolumn{2}{|c|}{$\begin{array}{c}\text { Hot Deal (with Hot } \\
\text { Net) }\end{array}$} \\
\cline { 2 - 5 } & $\begin{array}{c}\text { Power } \\
\text { purchase } \\
\text { cost }\end{array}$ & $\begin{array}{c}\text { Electricity } \\
\text { sales } \\
\text { revenue }\end{array}$ & $\begin{array}{c}\text { Hot } \\
\text { purchase } \\
\text { cost }\end{array}$ & $\begin{array}{c}\text { Sales } \\
\text { revenue }\end{array}$ \\
\hline $\begin{array}{c}\text { Winter } \\
\text { typical day }\end{array}$ & 18505.88 & 30507.17 & 1783.97 & 9968.82 \\
\hline $\begin{array}{c}\text { Summer } \\
\text { typical day }\end{array}$ & 11486.52 & 19445.90 & 756.86 & 234.34 \\
\hline $\begin{array}{c}\text { Typical Day } \\
\text { of the }\end{array}$ & 4292.45 & 11756,24 & 999.94 & 4871.57 \\
$\begin{array}{c}\text { Transition } \\
\text { Season }\end{array}$ & \multicolumn{3}{|c|}{} \\
\hline
\end{tabular}

\section{Conclusion}

Aiming at the problem of optimal allocation of regional integrated energy systems, a method for optimal allocation of integrated energy capacity that takes into account electric and thermal energy transactions is proposed, considering the energy interaction between the system and the energy bus (ie, upper-level power grid, heating network), based on system capacity planning and typical days The coupling of economic operation is optimized in two layers to maximize the economy and environmental protection of the system. Finally, the genetic algorithm is used to solve and verify its effectiveness and practicability. There will be many uncertainties in actual planning. Future research can focus on the impact of landscape volatility, load forecast error and energy price fluctuation sensitivity on the optimal allocation method.

\section{Acknowledgments}

This research was funded by the Science and Technology Project of the State Grid Corporation of China. The name of the project is the research of market integration transaction and typical business production simulation and benefit evaluation method of the integrated energy service system in Xiongan New District (Project No. SGHEJY00JJJS1900017).

\section{References}

1. WANG Jun, GU Wei, LU Shuai, et al. Coordinated planning of multi-district integrated energy system combining heating network model $[\mathrm{J}]$. Automation of Electric Power Systems, 2016, 40(15): 17-24.

2. BAHRAMI S. SHEIK HI A. From demand response in smart grid toward integrated demand response in smart energy hub [J]. IEEE Transactions on Smart Grid, 2016, 7(2): 650-658.

3. ZHAO Feng, ZHANG Chenghui, SUN Bo, et al.Three-stage collaborative global optimization design method of combined cooling heating and power [J].Proceedings of the CSEE, 2015, 35 (15): 3785-3793.

4. LIU Siyi, ZHAO Bo, WANG Xiangjin, et al. Coordinated control of active and reactive power fordistribution network with distributed photovoltaic based on model predictive control [J]. Automation of Electric Power Systems, 2017, 41(21): 119-126, 146.

5. WU Ming, REN Xuejing, ZHOU Dan, et al. Optimal allocation method for capacity of power supply system in industrial park under new electricity market reform $[\mathrm{J}]$. Automation of Electric Power Systems ,2018, 42(5): 2-8.

6. SALIMI M. GHASEMI H. ADELPOURM, et al Optimal planning of energy hubs in interconnected energy systems: A case study for natural gas and electricity [J]. IET Generation Transmission \&. Distribution, 2015, 9(8): 695-707. 